\title{
Diyarbakır Sulu Koşullarında II. Ürün Olarak Yetiştirilen Bazı Mısır Çeșitlerinde Verim ve Bazı Tarımsal Karakterler İle Karakterler Arası İlişkilerin Belirlenmesi
}

\author{
Bedirhan Sarikurt $^{1}$, Gülşah Bengisu ${ }^{2 *}$ \\ ${ }^{1}$ Harran Üniversitesi, Ziraat Fakültesi, Tarla Bitkileri Bölümü, Şanlıurfa, Türkiye (ORCID: 0000-0000-0000-0000) \\ ${ }^{2}$ Harran Üniversitesi, Ziraat Fakültesi, Tarla Bitkileri Bölümü, Şanlıurfa, Türkiye (ORCID: 0000-0003-1214-0011)
}

(İlk Geliş Tarihi 20 Ocak 2020 ve Kabul Tarihi 23 Şubat 2020)

(DOI: $10.31590 /$ ejosat.681220)

ATIF/REFERENCE: Sarikurt, B. \& Bengisu, G. (2020). Diyarbakır Sulu Koşullarında II. Ürün Olarak Yetiştirilen Bazı Mısır Çeşitlerinde Verim Ve Bazı Tarımsal Karakterler İle Karakterler Arası İlişkilerin Belirlenmesi. Avrupa Bilim ve Teknoloji Dergisi, (18), 243-247.

$\ddot{O} \mathbf{z}$

Bu çalışma Diyarbakır ekolojik şartlarında bazı melez mısır çeşitlerinde verim ve bazı tarımsal karakterler ile tarımsal karakterler arasındaki ilişkileri saptamak amacıyla, Diyarbakır ili Ergani ilçesi gülerce köyünde 2004 yılı II. ürün yetiştirme sezonunda yürütülmüştür. Araştırma, tesadüf blokları deneme desenine göre 3 tekrarlamalı olarak yürütülmüştür. Denemede 12 farklı mısır çeşidi kullanılmıştır. Bu çalışmada materyal olarak özel tohumculuk firmalarından temin edilen DK.585 (Dekalp), Progen 1595 (Özbuğday Tohum), Rx.770 (May), Trebia (May), Bora (May), Sele (May), Goldfrenk (Polen Tohumculuk), Folkner (Polen Tohumculuk), Goldeclat (Polen Tohumculuk), P.3394 (Pioneer), P.35P12 (Pioneer) ve P.33J56 (Pioneer) ticari melez mısır çeşitleri kullanıl mıştır. Çalışmada, tepe püskülü çiçeklenme süresi, bitki boyu, ilk koçan yüksekliği, bitki sap kalınlığı, koçan boyu, koçan çapı, koçanda tane sayısı, koçanda tanae ă̆ılrı̆̆ı, tane verimi parametreleri incelenmiştir. Araştırmada, tane verimleri 1137.67-1489.67 kg/da arasında değişim göstermiştir. Dk-585, RX-770, BORA ve GOLDECLAT çeşitleri yüksek verim vermiştir.

Anahtar Kelimeler: Mısır, ikinci ürün, verim, korelasyon, Diyarbakır

\section{Determination Research On The Determining Of Yield And Some Agricultural Characters And The Relationship Among The Characters On Maize Cultivars Grown As Second Crop Under Irrigated Conditions Of Diyarbakır Plain}

\begin{abstract}
This study was conducted to determine the yield and some agricultural characters and relationships among characters on maize cultivars grown as double crop under irrigation condictions of Diyarbakır Plain at the Gülerce Vilage of Ergani Town of Diyarbakır in double crop season of 2004. İt was designed as randomized blocks with three replications, it was tested 12 maize cultivars in experiment. In this study, DK.585 (Dekalp), Progen 1595 (Özbuğday Seed), Rx.770 (May), Trebia (May), Bora (May), Sele (May), Goldfrenk (Pollen Seed) obtained from private seed companies as materials, Folkner (Pollen Seed), Goldeclat (Pollen Seed), P.3394 (Pioneer), P.35P12
\end{abstract}

\footnotetext{
*Sorumlu Yazar: Harran Üniversitesi, Ziraat Fakültesi, Tarla Bitkileri Bölümü, Şanlırfa, Türkiye, ORCID: 0000-0003-1214-0011, gbengisu@hotmail.com
} 
(Pioneer) and P.33J56 (Pioneer) commercial hybrid corn varieties were used. In this study, the top tassel flowering time, plant height, first cob height, plant stalk thickness, cob height, cob diameter, grain number in cob, tanae weight in cob, grain yield parameters were investigated.In this study, grain yields were changed between 1137.67-1489.67 kg/da. Dk 585, RX 770, BORA and GOLDECLAT cultivars gave higher yield.

Keywords: Corn, second crop, yield, correlation, Diyarbakır

\section{Giriş}

Mısır, binlerce yıldan beri tarımı yapılan birkaç ender bitkiden biridir. Anavatanı Amerika kıtası olup buradan Dünya'nın her yerine yayıldığı bilinmektedir. A.B.D' nin New Mexico eyaletinde yapılan arkeolojik kazılarda, kayalardan oluşmuş barınaklarda ve mağaralarda bulunan mısır taneleri ve mısır koçanı parçalarının yaklaşık 5000 yıllık oldukları tespit edilmiştir. Öte yandan 1954 yılında, Meksika'nın başkenti Mexico City' de yapılan arkeolojik kazılarda ise, toprağın 50-60 m derinliğinde, yaklaşık 7000 yıllık olduğu belirlenen mısır çiçek tozlarına rastlanmıştır. Yabani mısır bugüne kadar bulunamadığı için, mısırın orijini ve tarihine ilişkin kesin bir bilgi elde edilememiş, bu konuda çeşitli teoriler üretilmiş ve hepsi de günümüzde hala tartışılmaktadır. Ancak, yapılan tüm arkeolojik kazılardan elde edilen bulgular, mısır bitkisinin 8.000 ile 10.000 yıllık bir geçmişi olduğunu göstermektedir.

Güneydoğu Anadolu bölgesinin özellikle Diyarbakır, Batman, Mardin ve Şanlıurfa mera alanlarının vejetasyon etüdleri sonucunda "zayıf mera" olduğunu bildiren pek çok araştırı vardır (Seydoşoğlu, 2018; Seydoşoğlu ve Kökten, 2018; Seydoşoğlu ve Kökten, 2019; Seydoşoğlu ve ark. 2018). Bu nedenle, II. ürün mısır yetiştiriciliği açısından son derece önemlidir. Çünkü, tane mısır hasadından sonra kalan mısır anızının hayvanların otlatılması açısından da önemlidir.

$\mathrm{Bu}$ çalışmanın amacı, Diyarbakır sulu koşullarında II. ürün olarak yetiştirilen bazı mısır çeşitlerinde verim ve bazı tarımsal karakterler ile karakterler arası ilişkilerin belirlenmesidir.

\section{Materyal ve Metot}

Bu araştırma, Diyarbakır İli Ergani İlçesi Gülerce Köyünde Hüdai Polat'a ait çiftçi tarlasında II. Ürün olarak 2004 yetiştirme sezonunda bir yıl süre ile yürütülmüştür. Bu çalışmada materyal olarak özel tohumculuk firmalarından temin edilen DK.585 (Dekalp), Progen 1595 (Özbuğday Tohum), Rx.770 (May), Trebia (May), Bora (May), Sele (May), Goldfrenk (Polen Tohumculuk), Folkner (Polen Tohumculuk), Goldeclat (Polen Tohumculuk), P.3394 (Pioneer), P.35P12 (Pioneer) ve P.33J56 (Pioneer) ticari melez misir çeşitleri kullanılmışıı. Deneme alanları yarı-kurak ve çok sıcak iklim koşullarının oluşturduğu, kırmızı kahverengi büyük toprak gurubuna giren, düz ya da düze yakın eğimlerde, derin veya orta derin $\mathrm{ABC}$ profilli zonal topraklardır. Diyarbakır ilinde, yıllık yağışın yaklaşık olarak tamamı Ekim ve Mayıs ayları arasında düşmektedir. Yaz aylarında hemen hiç yağış görülmemekte, hava oransal nemi de düşük olduğundan toprak evaporasyonla çok hızlı su kaybetmektedir. Araştırmanın yürütüldüğü aylara ve uzun yıllara ait bazı iklim değerleri Tablo 1'de verilmiştir.

Tablo 1. Diyarbakır iline ait bazı iklim verileri

\begin{tabular}{|c|c|c|c|c|c|}
\hline Aylar & $\begin{array}{c}\text { Ortalama Sıcaklık } \\
\left({ }^{\circ} \mathrm{C}\right)\end{array}$ & $\begin{array}{c}\text { En Yüksek } \\
\text { Sicaklık } \\
\left({ }^{\circ} \mathrm{C}\right)\end{array}$ & $\begin{array}{c}\text { En Düşük } \\
\text { Sicaklık } \\
\left({ }^{\circ} \mathrm{C}\right)\end{array}$ & $\begin{array}{c}\text { Toplam Yağış } \\
(\mathbf{m m})\end{array}$ & $\begin{array}{c}\text { Nispi Nem } \\
\%\end{array}$ \\
\hline \multirow[t]{2}{*}{ Haziran } & 26.4 & 33.8 & 16.4 & 16.0 & 23.3 \\
\hline & 25.9 & & & 7.2 & 36 \\
\hline \multirow{2}{*}{ Temmuz } & 31.4 & 38.2 & 20.7 & 0.0 & 11.9 \\
\hline & 31.0 & & & 0.7 & 27 \\
\hline \multirow[t]{2}{*}{ Ağustos } & 30.0 & 37.5 & 20.5 & 0.0 & 14.1 \\
\hline & 30.3 & & & 0.6 & 27 \\
\hline \multirow[t]{2}{*}{ Eylül } & 25.0 & 34.0 & 15.3 & 0.0 & 19.0 \\
\hline & 24.9 & & & 2.6 & 31 \\
\hline \multirow[t]{2}{*}{ Ekim } & 18.2 & 26.7 & 10.8 & 1.3 & 41.2 \\
\hline & 17.1 & & & 30.8 & 48 \\
\hline \multirow[t]{2}{*}{ Kasım } & 8.1 & 13.9 & 3.7 & 123.1 & 69.4 \\
\hline & 9.8 & & & 54.6 & 68 \\
\hline
\end{tabular}

Tablo 1'den izleneceği üzere denemenin yürütüldüğü dönemde en düşük ortalama sıcaklık $8.1^{\circ} \mathrm{C}$ ile Kasım ayında; en yüksek ortalama sıcaklık $31.4{ }^{\circ} \mathrm{C}$ ile Temmuz ayında saptanmıştır. Uzun yıllar ortalama sıcaklık değerlerine bakıldığında en düşük ortalama sıcaklığın $9.8{ }^{\circ} \mathrm{C}$ ile Kasım ayında, en yüksek ortalama sıcaklığın ise $31.0{ }^{\circ} \mathrm{C}$ ile Temmuz ayında saptandığı gözlenmiştir. Deneme süresince gerçekleşen yağışa bakıldığında; en düşük toplam yağışın $0 \mathrm{~mm}$ ile Temmuz, ağustos ve eylül aylarında, en yüksek toplam yağışın $123.1 \mathrm{~mm}$ ile Kasım ayında saptandığı gözlenmiştir. Uzun yıllar ortalama değerlerine bakıldığında toplam yağış miktarının en düşük $0.6 \mathrm{~mm}$ ile Ağustos ayında, en yüksek $54.6 \mathrm{~mm}$ ile Kasım ayında saptandığı gözlenmiştir. Nispi nem değerlerine bakıldığında ise denemenin yürütüldüğü dönemde en düşük nispi nem değeri \% 11.9 ile Temmuz ayında, en yüksek nispi nem değeri \% 69.4 ile Kasım 
ayında kaydedilmiştir. Nispi nem değerleri bakımından uzun yıllar değerlerine bakıldığında en düşük nispi nem \%27 ile Temmuz ve Ağustos aylarında, en yüksek nispi nem \% 68 ile Kasım ayında saptanmıştır.

Deneme Tesadüf Blokları Deneme desenine göre üç tekrarlamalı olarak kurulmuştur. Denemede her bir parsel 4 ekim sırasından oluşturulmuştur. Denemede, sıra arası $70 \mathrm{~cm}$, sıra üzeri $20 \mathrm{~cm}$, sıra uzunluğu $5 \mathrm{~m}$, parsel alanı $14 \mathrm{~m}^{2}$, hasatta parsel alanı ise $7 \mathrm{~m}^{2}$ oluşmuştur. Denemede bloklar arasında çeşitli bakım işlemlerine kolaylık sağlaması bakımından $2 \mathrm{~m}$ boşluk bırakılmıştır ve bakım işlemlerinin tamamı zamanında uygulanmıştır. Buğday hasadından sonra ekime hazırlanan deneme alanında $2.8 \times 5 \mathrm{~m}=14 \mathrm{~m} 2$ büyüklüğündeki parsellere, her ocağa iki tohum gelecek şekilde elle ekim yapılmıştır. Ekim 02/07/2004 tarihinde el ile yapılmıştır. Ekimden hemen sonra karık usulü sulama yapılmıştır. Ekimden önce deneme alanına dekara $10 \mathrm{~kg} / \mathrm{da}$ saf azot ve $10 \mathrm{~kg} / \mathrm{da}$ saf fosfor gelecek şekilde 20.20.0 kompoze gübresi uygulanmıştır. Ayrıca, bitkiler 40-50 cm boylandığında üst gübre olarak dekara $10 \mathrm{~kg}$ saf azot gelecek şekilde üre verilmiştir. Çıkıştan sonra bitkiler iki-üç yapraklı dönemde iken seyreltme yapılmıştır. Gübre uygulamalarından sonra ve yetiştirme süresince toplam 6 kez sulama yapılmıştır. Sulamalar karıklara su verilmek suretiyle yapılmıştır. Çıkış sonrası görülen yabancı otlar el çapası ile çapalanmak suretiyle yok edilmiştir. Hasat; 02 Kasım 2004 tarihinde ortadaki iki sıradan koçanlar elle koparılmak, toplanmak suretiyle yapılmış, diğer iki sıra ise kenar tesiri olarak hasat edilmemiştir.

VerilerindDeğerlendirmeleri MSTAT-C istatistik paket programı kullanılarak tesadüf blokları deneme desenine göre varyans analizi yapılmıştır. Etkili farklılıkları görmek için F testi kullanılmıştır. Ortalama değerler arasındaki karşılaştırmalar Duncan (\%5) testine göre yapılmıştır.

\section{Araştırma Sonuçları ve Tartışma}

Tepe püskülü çiçeklenme süresi (gün) yönünden çeşitler arasında fark önemli çıkmıştır(p<0.05). Yapılan LSD (\%5) testine göre çeşitler arasında tepe püskülü çiçeklenme süresi (gün) yönünden 4 farklı grup oluşmuştur. Tepe püskülü çiçeklenme süresi değerleri 71.00 -74.67 gün arasında değişim göstermiştir (Tablo 2). En yüksek tepe püskülü çiçeklenme süresi değeri 74.67 gün ile P 35P12 çeşidinden elde edilmiş, en düşük tepe püskülü çiçeklenme süresi değeri ise 71.00 ile RX 770, GOLDFRENK ve P $33 J 56$ çeşitlerinde gözlenmiş̧ir.

Tablo 2. Araştırmada İncelenen Bazı Özellikler

\begin{tabular}{llllll}
\hline ÇEŞiTLER & $\begin{array}{l}\text { Tepe Püskülü } \\
\text { Çiçeklenme } \\
\text { süresi (gün) }\end{array}$ & $\begin{array}{l}\text { Bitki Boyu } \\
\mathbf{( c m )}\end{array}$ & $\begin{array}{l}\text { İk Koçan } \\
\text { Yüksekliği } \\
\text { (cm) }\end{array}$ & $\begin{array}{l}\text { Bitki Sap } \\
\text { Kalınlığı } \\
\text { (mm) }\end{array}$ & $\begin{array}{l}\text { Koçan Boyu } \\
\text { (cm) }\end{array}$ \\
\hline DK 585 & $71.33 \mathrm{c}$ & 289.30 & 88.57 & 36.40 & $19.41 \mathrm{a}$ \\
PROGEN 1595 & $72.00 \mathrm{bc}$ & 270.47 & 92.00 & 36.73 & $18.59 \mathrm{ab}$ \\
RX 770 & $71.00 \mathrm{c}$ & 253.53 & 94.67 & 35.13 & $18.88 \mathrm{ab}$ \\
TREBIA & $73.67 \mathrm{ab}$ & 282.13 & 99.53 & 36.76 & $17.10 \mathrm{a}-\mathrm{c}$ \\
BORA & $74.33 \mathrm{a}$ & 256.50 & 79.63 & 36.80 & $16.52 \mathrm{bc}$ \\
SELE & $72.33 \mathrm{bc}$ & 282.90 & 98.73 & 35.80 & $14.50 \mathrm{c}$ \\
GOLDFRENK & $71.00 \mathrm{c}$ & 286.57 & 102.67 & 35.53 & $17.65 \mathrm{ab}$ \\
FOLKNER & $71.33 \mathrm{c}$ & 284.23 & 104.57 & 34.40 & $17.37 \mathrm{ab}$ \\
GOLDECLAT & $71.67 \mathrm{c}$ & 267.27 & 96.43 & 35.06 & $18.50 \mathrm{ab}$ \\
P 3394 & $73.67 \mathrm{ab}$ & 281.70 & 99.20 & 34.33 & $16.08 \mathrm{bc}$ \\
P 35P12 & $74.67 \mathrm{a}$ & 254.30 & 84.40 & 33.40 & $16.09 \mathrm{bc}$ \\
P 33J56 & $71.00 \mathrm{c}$ & 271.03 & 101.70 & 35.86 & $16.38 \mathrm{bc}$ \\
\hline ORTALAMA & 72.33 & 273.33 & 95.18 & 35.52 & 17.25 \\
LSD (\%5) & 1.687 & Ö.D. & Ö.D. & O.D. & 2.50 \\
\hline
\end{tabular}

Tablo 2 incelendiğinde; bitki boyu yönünden çeşitler arasında fark önemli değildir ( $\mathrm{p}>0.05$ ). Bitki Boyu değerleri $253.53-289.30$ $\mathrm{cm}$ arasında değişim göstermiştir. En yüksek Bitki boyu değeri $289.30 \mathrm{~cm}$ ile DK 585 çeşidinden elde edilmiş, en düşük Bitki Boyu değeri ise $253.53 \mathrm{~cm}$ ile RX 770 çeşidinde gözlenmiştir.

Varyans analiz sonuçlarına göre mısır bitkisinde ilk koçan yüksekliği $(\mathrm{cm})$ yönünden çeşitler arasında fark önemli değildir (Tablo 2). İlk koçan yüksekliği değerleri $79.63-104.57 \mathrm{~cm}$ arasında değişim göstermiştir. En yüksek ilk koçan yüksekliği değeri $104.57 \mathrm{~cm}$ ile FOLKNER çeşidinden elde edilmiş, en düşük ilk koçan yüksekliği değeri ise $79.63 \mathrm{~cm}$ ile BORA çeşidinde gözlenmiştir.

Tablo 2'de görüldüğü gibi varyans analiz sonuçlarına göre mısır bitkisinde bitki sap kalınlığı (mm) yönünden çeşitler arasında fark önemli değildir. Bitki sap kalınlığı değerleri 33.40-36.80 mm arasında değişim göstermiştir. En yüksek sap kalınlığı değeri 36.800mm ile P 35P12 çeşidinden elde edilmiş, en düşük sap kalınlığı değeri ise 33.400mm ile P 35P12 çeşidinde gözlenmiştir. 
Mısır bitkisinde koçan boyu (cm) yönünden çeşitler arasında fark önemli çıkmıştır. Yapılan LSD (\%5) testine göre çeşitler arasında koçan boyu yönünden 5 farklı grup oluşmuştur. Koçan boyu değerleri $14.50-19.41 \mathrm{~cm}$ arasında değiş̧im göstermiştir. En yüksek koçan boyu değeri $19.41 \mathrm{~cm}$ ile DK 585 çeşidinden elde edilmiş, en düşük koçan boyu değeri ise $14.50 \mathrm{~cm}$ ile SELE çeşidinde gözlenmiştir.

Tablo 3. Mısırın Koçan İle İlgili Bazı Özellikler

\begin{tabular}{lllll}
\hline ÇEŞiTLER & Koçan Çapı (cm) & $\begin{array}{l}\text { Koçanda Tane Sayısı } \\
\text { (adet) }\end{array}$ & $\begin{array}{l}\text { Koçanda Tane } \\
\text { Ağırlığı (g/koçan) }\end{array}$ & Tane Verimi (kg/da) \\
\hline DK 585 & $48.37 \mathrm{ab}$ & 674.90 & 206.00 & 1489.67 \\
PROGEN 1595 & $49.07 \mathrm{ab}$ & 581.07 & 200.00 & 1428.00 \\
RX 770 & $50.50 \mathrm{a}$ & 603.23 & 206.00 & 1470.67 \\
TREBIA & $49.30 \mathrm{ab}$ & 619.17 & 183.33 & 1286.67 \\
BORA & $50.27 \mathrm{ab}$ & 668.70 & 202.67 & 1447.00 \\
SELE & $49.80 \mathrm{ab}$ & 652.90 & 159.33 & 1137.67 \\
GOLDFRENK & $45.27 \mathrm{c}$ & 520.43 & 175.33 & 1251.67 \\
FOLKNER & $47.43 \mathrm{bc}$ & 708.43 & 194.67 & 1389.67 \\
GOLDECLAT & $47.40 \mathrm{bc}$ & 636.47 & 202.67 & 1447.00 \\
P 3394 & $47.37 \mathrm{bc}$ & 581.50 & 183.33 & 1308.67 \\
P 35P12 & $57.83 \mathrm{a}-\mathrm{c}$ & 532.17 & 193.33 & 1380.00 \\
P 33J56 & $48.60 \mathrm{ab}$ & 556.80 & 165.33 & 1180.67 \\
\hline ORTALAMA & 48.43 & 611.31 & 189.33 & 1351.44 \\
LSD (\%5) & 2.538 & O.D. & O.D. & Ö.D. \\
\hline
\end{tabular}

Koçan çapı $(\mathrm{mm})$ yönünden çeşitler arasında fark önemli çıkmışırı( $\mathrm{p}<0.05)$. Yapılan LSD $(\% 5)$ testine göre çeşitler arasında koçan çapı yönünden 5 farklı grup oluşmuştur. Koçan çapı değerleri 45.27-50.50 mm arasında değişim göstermiştir. En yüksek koçan çapı değeri $50.50 \mathrm{~mm}$ ile RX 770 çeşidinden elde edilmiş, en düşük koçan çapı değeri ise $45.27 \mathrm{~mm}$ ile GOLDFRENK çeşidinde gözlenmiş̧ir.

Koçanda tane sayısı (adet) yönünden çeşitler arasında fark önemli değildir(p>0.05). Koçanda Tane Sayısı değerleri $520.43-708.43$ adet arasında değişim göstermiştir. En yüksek koçanda tane sayısı değeri $104.57 \mathrm{~cm}$ ile FOLKNER çeşidinden elde edilmiş, en düşük koçanda tane sayısı değeri ise 520.43 adet ile GOLDFRENK çeşidinde gözlenmiştir.

Tablo 3’te görüldüğü gibi varyans analiz sonuçlarına göre mısır bitkisinde koçanda tane ağırlı̆ğ (gr/koçan) yönünden çeşitler arasında fark önemli değildir(p>0.05). Koçanda tane ağıllı̆̆ değerleri $159.33-206.00$ (gr/koçan) arasında değişim göstermiştir. En yüksek koçanda tane ağırlığı değeri 206.00 (gr/koçan) ile RX 770 ve DK 585 çeşitlerinden elde edilmiş, en düşük koçanda tane ağırlığı değeri ise 159.33 (gr/koçan) ile SELE çeşidinde gözlenmiştir.

Varyans analiz sonuçlarına göre mısır bitkisinde tane verimi (kg/da) yönünden çeşitler arasında fark önemli değildir(p $>0.05)$. Tane verimi değerleri $1137.67-1489.67$ (kg/da) arasında değişim göstermiştir. En yüksek tane verimi değeri 1489.67 (kg/da) ile DK 585 çeşidinden elde edilmiş, en düşük tane verimi değeri ise $1137.67(\mathrm{~kg} / \mathrm{da})$ ile SELE çeşidinde gözlenmiştir.

Tüm özellikler açısından incelendiğinde; birçok araştıııcının bulgularıyla benzerlikler ve farklılıklar olduğu tespit edilmiştir (Turan ve Yılmaz, 2000; Keskin ve ark. 2005; Kılıç ve Gül, 2007; Tezel, 2007; Elmalı ve Soylu 2008; Erdal, 2016, Taş ve ark. 2016; Okay ve Yazgan, 2016; Seydoşoğlu ve Saruhan 2017; Gür ve Kara, 2019; Özdemir ve Sade, 2019; Ağaçkesen ve Öktem, 2020). Bu farklılığın nedeni olarak, denemede kullanılan çeşitlerin, topak yapısının, ekolojik faktörlerden, çeşitlerin genetik yapılarından kaynaklandığı söylenebilir.

\section{Sonuç}

$\mathrm{Bu}$ çalışmada; verim yönünden çeşitler arasında fark oluşmadığı görülmektedir. Çeşit seçiminde; bölgemize uygun çeşitler seçilmiş olup en uygun çeşit seçimine gidilmiştir. Çeşitler arasında tane verimi yönünden fark istastiki olarak önemli çıkmamıştır. Ancak üreticileri yönlendirmek açısından diğer çeşitlere oranla daha yüksek verimli bulunan DK.585, PROGEN 1595, RX 770, BORA VE GOLDECLAT gibi çeşitler Diyarbakır İli bölgesinde yetiştirilebileceği tasfiyesi edilebilir. 


\section{Açıklama}

Bu çalışmanın verileri, ilk yazarın yüksek lisans tezinden alınarak yapılmıştır.

\section{Kaynakça}

Ağaçkesen, M.N., \& Öktem, A. (2020). Farklı zamanlarda yapılan hasadın merit tatlı mısır çeşidinde (Zea mays L. saccharata Sturt) taze koçan verimi ve bazı verim unsurlarına etkisi. KSÜ Tarım ve Doğa Dergisi 23 (1): 69-76.

Elmalı, H., \& Soylu, S. (2008). Melez atdişi mısırda farklı taban gübresi çeşitlerinin tane verimi, verim unsurları ve kalite üzerine etkileri. Selçuk Tarım ve Glda Bilimleri Dergisi, 22(44), 104-112.

Erdal, S. (2016). Mısırda normal ve kuraklık stresi koşullarında tane verimi ile ilişkili seleksiyon kriterlerinin belirlenmesi. Derim, 33(1), 131-143.

Gür, İ., \& Kara, B. (2019). Trabzon ekolojik koşullarında bazı hibrit atdişi mısır çeşitlerinin (zea mays ındentata sturt) performansları. Black Sea Journal of Agriculture 2(2): 103-108

Keskin, B., Akdeniz, H., Yılmaz, İ.H., \& Turan, N. (2005). Yield and quality of forage corns (Zea mays L.) as influenced by cultivar and nitrogen rate. Journal of Agronomy 4(2), 138-141.

Kılıç, H., Gül, İ. (2007). Hasat zamanının diyarbakır şartlarında ikinci ürün olarak yetiştirilen mısır çeşitlerinde verim ve bazı tarımsal karakterler ile silaj kalitesine etkileri üzerine bir araştırma. Harran Üniversitesi Ziraat Fakülesi Dergisi, 11(3-4),43-52.

Okay, D., \& Yazgan, S. (2016). Farklı su uygulama düzeylerinin mısır bitkisi verimi üzerine etkisi. Uludağ Üniversitesi Ziraat Fakültesi Dergisi 30(1), 1-12.

Özdemir, E., \& Sade, B. (2019). Atdişi mısır (Zea mays indentata Sturt.) genotiplerinde verim ve verim unsurlarının genetik analizi. Bursa Uludă̆ Üniversitesi Ziraat Fakültesi Dergisi. 33(1), 83-92.

Seydoşoğlu, S. (2018). Bazı doğal mera alanlarının bitki örtüsü özellikleri, mera durumu ve sağlığının belirlenmesi, Türkiye Ormancılık Dergisi, 19(4), 368-373.

Seydoşoğlu, S., \& Kökten, K. 2018. Batman ili beşiri ilçesi mera vejetasyonlarının bazı özellikleri, Ege Üniversitesi Ziraat Fakültesi Dergisi, 55(4), 491-497.

Seydoşoğlu, S., Kökten, K., \& Sevilmiş, U. (2018). Basic vegetation characteristics of village pastures connected to mardin province and its provinces, Turkish Journal of Agricultural and Natural Sciences, 5(4), 406-413.

Seydoşoğlu, S., \& Saruhan, V. (2017). Farklı ekim zamanlarının bazı silajlık mısır çeşitlerinde verim ve verim unsurlarına etkisinin belirlenmesi. Ege Üniversitesi Ziraat Fakültesi Dergisi, 54 (4), 377-383.

Seydoşoğlu, S., \& Kökten, K. (2019). Batman mera vejetasyonlarının bazı özellikleri, Harran Tarım ve Gıda Bilimleri Dergisi, 23(1), 27-33.

Taş, T., Öktem, A.G, Öktem, A., \& Sürücü, A. (2016). Harran ovası koşullarında yetiştirilen mısır bitkisinde (Zea Mays L. İndentata) farklı ekim sıklığının silaj verimi ve bazı tarımsal özelliklere etkisi. Tarla Bitkileri Merkez Araştırma Enstitüsü Dergisi, 25, 64-69.

Tezel, M. (2007). Mısırda (Zea mays L.) verim ve verim unsurları için kalıtım parametrelerinin belirlenmesi. Yüksek Lisans Tezi. S.Ü. Fen Bilimleri Enstitüsü, 128s,

Turan, N., \& Yılmaz, İ. (2000). Van koşullarında I. ve II. ürün olarak yetiştirilen bazı silajlık mısır çeşitlerinin hasıl verim ve bazı verim unsurlarının belirlenmesi. Atatürk Üniversitesi Ziraat Fakültesi Dergisi 31(2), 63-71. 